\section{СОЦИОЛОГИЧЕСКИЙ АНАЛИЗ ЗАКОНОДАТЕЛЬНЫХ АКТОВ О ПРАВАХ ЖЕНЩИН В РОССИИ}

\section{Аннотация:}

Статья посвящена обзору законодательных актов, проектов и национальных стратегий, гарантирующих гендерное равноправие в России. Выявляется, насколько объективно в них освещен вопрос дискриминации женщин и действительно ли принятые законопроекты и указы реализуются в общественной жизни. Рассмотрение этих документов в хронологическом порядке позволяет выявить наиболее острые проблемы, на которые обращали внимание специалисты в тот или иной момент времени. Подробно описана последняя национальная стратегия - на 2017-2022 г2., которая получила как положительные, так и отрицательные оценки. Однако именно она, по словам экспертов в области гендерных исследований и решения женского вопроса, наиболее детально разработана, соответствует действительному положению дел в обществе и дает реальные рекомендации по реализации содержащихся в ней мер.

\section{Ключевые слова:}

борьба за права женщин, женское движение, гендерное неравенство, законодательные акты, национальная стратегия, гендерная дискриминация, гендерный дисбаланс, социологическое исследование.
PhD student, Contemporary Sociology Subdepartment, Sociology Department, Lomonosov Moscow State University

\section{A SOCIOLOGICAL ANALYSIS OF LEGISLATIVE INSTRUMENTS CONCERNING WOMEN'S RIGHTS IN RUSSIA}

Summary:

The study reviews legislative instruments, projects, and national strategies guaranteeing gender equality in Russia. The author reveals how they cover the issue of discrimination against women and whether the adopted draft laws and decrees are implemented in public life. The chronological review of the above-mentioned documents identifies the most acute problems which are considered by experts from time to time. The research describes the last National Strategy for 2017-2022 which has both positive and negative points. However, according to the experts in gender studies and women's issue, this strategy is more elaborate, corresponds to the real situation in society, and provides recommendations for its implementation.

C начала XX в. женщины борются за равные права с мужчинами: в политике, экономике, социальной и семейной сферах. В результате им было предоставлено множество прав, например избирательное, однако дискриминация по полу продолжает существовать и гендерный дисбаланс стараются ликвидировать в первую очередь на законодательном уровне.

В рамках статьи определяется, в каких законодательных актах РФ закреплено равенство прав между мужчинами и женщинами, насколько объективно освещен вопрос дискриминации женщин и действительно ли принятые законопроекты и указы реализуются в общественной жизни. Кратко представлено содержание указов, начиная от Конституции РФ 1993 г., и более подробно рассмотрены последние принятые национальные проекты вплоть до 2022 г., которые активно обсуждаются в СМИ, на научных форумах и среди политических деятелей.

Конституция РФ содержит статьи, гарантирующие гендерное равноправие: статья 19 провозглашает, что в России мужчина и женщина имеют равные права и свободы; статья 37 гарантирует равное вознаграждение за труд людям вне зависимости от пола; статья 38 провозглашает, что забота о детях и их воспитание - равное право и обязанность обоих родителей [1]. Однако не существует каких-либо специальных служб или органов, которые отвечали бы за предупреждение и ликвидацию дискриминации [2].

Начиная с 1993 г. принимались указы, преследовавшие цель «улучшения социально-экономического статуса женщин», например Указ Президента РФ от 4 марта 1993 г. № 337 «О первоочередных задачах государственной политики в отношении женщин» [3].

В 1995 г. В Пекине прошла IV Всемирная конференция ООН по положению женщин [4]. Участие Российской Федерации в конференции способствовало разработке в России документов и мер по улучшению положения женщин, особенно в связи с тем, что участились случаи нарушения прав женщин в сорере труда, ухудшилось их материальное положение. 
В 1996-1997 гг. разрабатывались планы и концепции, которые должны были способствовать улучшению положения женщин в обществе, а именно: ликвидации низкого уровня политического представительства женщин, предоставлению им социально-трудовых прав; предотвращению насилия; охране репродуктивного здоровья, материнства и др. Однако в этих документах не были прописаны меры по реализации планов, некоторые планы не получили материального обеспечения, в связи с чем так и остались неосуществленными [5].

В 2000-х гг. также создавались национальные проекты и гендерные стратегии, но своими целями они ставили не достижение гендерного равноправия, а укрепление семейных отношений, сохранение традиционных ценностей родительства, материнства и отцовства. Многие задачи, которые были прописаны в этих проектах, не были конкретизированы, не определялись ресурсы для их выполнения. В документах не отражались такие важные проблемы, как дискриминация женщин на рынке труда, слабая представленность женщин в органах власти [6].

Наиболее проработанная гендерная стратегия создается в 2004 г. Представленные в ней мероприятия затрагивали 2008-2015 гг. Ее авторы исходили из того, что существует гендерный дисбаланс в экономической сфере, женщины слабо представлены в системе государственного управления, семейные обязанности между супругами поделены неравномерно, воспитание детей полностью возложено на плечи женщин, и этот труд никак не компенсируется в денежном эквиваленте. В рамках данной стратегии для достижения гендерного равенства прописаны меры, которые предполагалось осуществить за указанный срок, а именно: увеличение представительства женщин в органах власти; внедрение гендерной экспертизы законов, программ и проектов; расширение гендерной статистики; проведение просветительских кампаний, направленных на повышение уровня гендерной культуры российского населения [7].

Этот проект демонстрирует положительную динамику в обществе по отношению к женщинам: выплачиваются пособия и материнский капитал для поддержания материального состояния семьи, создаются женские общества, которые способствуют продвижению женщин по карьерной лестнице и поддержке женщин-предпринимателей, все чаще женщины становятся членами политических партий и органов управления.

Однако многие задачи не были решены в рамках данной стратегии, поставленные цели не были достигнуты. В связи с этим была разработана Национальная стратегия на 2017-2022 гг. [8]. В подготовке данного документа были задействованы социологи, политологи, специалисты в области изучения гендерного вопроса.

Разберем ее содержание, а также проанализируем отзывы специалистов, которые оценивали значимость и выполнимость данного документа в российском обществе.

Данная стратегия отличается большей проработанностью и приведением актуальных статистических данных. Зафиксировано, что в Российской Федерации на начало 2016 г. проживает 146,5 млн чел., из них женщины составляют 78,6 млн - более половины населения страны. Отмечается, что последние обладают высоким уровнем образования и экономической активностью. Это подтверждается следующими цифрами: среди высококвалифицированных научных кадров женщины составляют 25 \% среди докторов наук и 41 \% среди кандидатов наук. Однако их интеллектуальный потенциал используется не в полной мере. Число женщин - руководителей организаций снизилось с 37,3 \% в 2006 г. до 32,7 \% в 2015 г. При этом наблюдается разница в заработных платах между мужчинами и женщинами. У последних она ниже, хотя разница постепенно сокращается: в 2011 г. заработная плата женщин составляла 67,9 \% средней заработной платы мужчин, а в 2015 г. - уже $72,6 \%$.

В политической сфрере наблюдается повышение активности женщин в управлении государством. На государственной службе доля женщин составляет 72,1 \%, в центральных аппаратах федеральных органов эта цифра составляет 59 \%, в том числе 25,3 \% женщин выступают в качестве руководителей. В дипломатическом секторе доля женщин увеличилась и составляет $16 \%$, в то время как в 2010 г. эта цифра составляла всего 10,8\%.

Можем отметить, что представительство женщин в политике закреплено на законодательном уровне, однако реальное включение их в списки кандидатов в депутаты и на иные выборные должности в органах государственной власти на практике реализуется медленно.

Помимо статистических данных в документе детально выявлены механизмы и ресурсы для его реализации. В первую очередь прописано, что должен быть создан Координационный совет при Правительстве РФ, целями которого являются создание проектов, гарантирующих гендерное равноправие, и реализация данных проектов. Также предполагаются совершенствование законодательства с учетом общепризнанных норм международного права, проведение научных исследований и различных видов мониторинга по вопросам обеспечения равноправия женщин и мужчин. В этом документе оговариваются более серьезная поддержка предпринимательской деятельности женщин, обеспечение их самозанятости. Предусмотрено привлечение ресурсных центров некоммерческих организаций и центров инноваций социальной сферы. 
В рамках Стратегии прописаны ожидаемые результаты, к которым должны прийти к 2022 г. Большое внимание уделяется сокращению разницы в оплате труда между мужчинами и женщинами, что позволит улучшить материальное положение семьи, и в частности неполных семей с матерью-одиночкой. Также оговорено развитие малого и среднего бизнеса с женщиной во главе, увеличение числа женщин-предпринимателей. Предполагается сокращение числа рабочих мест с вредными и (или) опасными условиями труда, на которых работают женщины. В социальной сфере должно наблюдаться сокращение числа случаев насилия в отношении женщин. В политической сфере необходимо увеличение доли женщин на государственной службе. Также прописано, что для мониторинга результатов Стратегии необходимы проведение социологических исследований и более полное отражение в системе статистического наблюдения данных, характеризующих положение женщин в политической, экономической, социальной и культурной сферах [9].

Сразу же после публикации Стратегия действий в интересах женщин получила не только положительные, но и негативные оценки. В частности, многие эксперты задавали вопрос: зачем создавать еще один инструмент, если гендерное равноправие закреплено Конституцией? К тому же до начала реальных дел предстояло осуществить множество действий: от создания Координационного совета до разработки конкретных нормативных актов и их утверждения. Также задавался вопрос о фринансировании мероприятий Стратегии [10].

Однако большинство экспертов склоняются к тому, что данный документ является наиболее проработанным, чем все предыдущие, он будет способствовать достижению целей, которые в нем прописаны. Специалисты отмечают, что «она сделана более конкретно, чем предыдущие расплывчатые документы... женщины, которые влияли на то, чтобы такая стратегия была принята, ...выполнили свою миссию, и мы сегодня с вами имеем до 2022 г. очень хороший исходный документ как стартовый документ» [11].

Таким образом, результаты анализа содержания основных документов, способствующих ликвидации гендерного дисбаланса в России, и выявление хронологии их принятия показали, что последние проекты наиболее проработаны и соответствуют целям, в них заявленным. Действующая на данный момент Национальная стратегия является итогом коллективного творчества как политических деятелей, так и специалистов в женском вопросе и гендерных исследованиях, и только благодаря комплексному изучению вопроса, общему вкладу можно добиться высоких результатов. Для реализации положений данного документа необходима серьезная работа. По истечении срока будут проведены научные исследования, подведены итоги того, какие реальные результаты были получены за счет введения данной Стратегии, и на основании уже полученного анализа можно будет предпринимать дальнейшие действия, способствовать созданию новых проектов и стратегий и воплощать их в жизнь.

\section{Ссылки:}

1. Конституция РФ 1993 г. [Электронный ресурс] : принята всенар. голосованием (референдумом) 12 дек. 1993 г. Доступ из справ.-правовой системы «КонсультантПлюс».

2. Воронина О.А. Феминизм и гендерное равенство. М., 2003. 320 с.

3. О первоочередных задачах государственной политики в отношении женщин [Электронный ресурс] : указ Президента РФ от 4 марта 1993 г. № 337. Доступ из справ.-правовой системы «Гарант».

4. Report of the Fourth World Conference on Women (Beijing, 4-15 September 1995) [Электронный ресурс]. N. Y., 1996. 233 p. URL: http://www.un.org/womenwatch/daw/beijing/pdf/Beijing\%20full\%20report\%20E.pdf (дата обращения: 12.03.2018).

5. О Концепции законотворческой деятельности по обеспечению равных прав и равных возможностей мужчин и женщин [Электронный ресурс] : постановление Государственной думы Федерального Собрания РФ от 20 нояб. 1997 г. № 1929-ІІ ГД. Доступ из справ.-правовой системы «Гарант» ; Об утверждении национального плана действий по улучшению положения женщин и повышению их роли в обществе до 2000 г. : постановление Правительства РФ от 29 авг. 1996 г. № 1032 [Электронный ресурс]. Доступ из справ.-правовой системы «Гарант».

6. Гендерная стратегия Российской Федерации [Электронный ресурс] / Министерство труда и социального развития Российской Федерации. М., 2002. URL: http://www.owl.ru/win/docum/rf/strategy/strategy.htm (дата обращения: 16.01.2018) ; О Национальном плане действий по улучшению положения женщин в Российской Федерации и повышению их роли в обществе на 2001-2005 гг. [Электронный ресурс] : распоряжение Правительства РФ от 28 июня 2001 г. № 855-p. URL: https://www.lawmix.ru/pprf/57931 (дата обращения: 16.01.2018).

7. Гендерная стратегия Российской Федерации [Электронный ресурс] / Министерство труда и социального развития Российской Федерации. М., 2004. URL: http://womnet.ru/prava/2004/1/4.htm (дата обращения: 20.01.2018).

8. Национальная стратегия действий в интересах женщин на 2017-2022 гг. [Электронный ресурс] : распоряжение Правительства РФ от 8 марта 2017 г. № 410-p. URL: http://eawfpress.ru/about/organizatsiyam/strategia2017.php (дата обращения: 23.01.2018).

9. Там же.

10. Борисова О. Утверждена Национальная стратегия в интересах женщин [Электронный ресурс]. 2017. 23 марта. URL: http://subsidii.net/ещё-выплаты/новости-о-разном/item/1128-национальная-стратегия-женщин.html (дата обращения: 23.01.2018)

11. Материалы VII Социологической Грушинской конференции «Навстречу будущему. Прогнозирование в социологических исследованиях». Секция «Будущее уже рядом - II. Трансформация гендерных ролей: от прошлого к будущему» [Электронный ресурc]. М., 2017. URL: https://wciom.ru/index.php?id=1049 (дата обращения: 20.05.2017). 


\section{References:}

Borisova, O 2017, The National Strategy for Women Is Approved, March 23, viewed 23 January 2018, <http://subsidii.net/ещё-выплаты/новости-о-разном/item/1128-национальная-стратегия-женщин.html>, (in Russian).

Proceedings of the VII Sociological Grushin Conference "Towards the Future. Forecasting in Social Studies". Section "The future is near - II. Transformation of gender roles: from past to future" 2017, Moscow, viewed 20 May 2017, <https://wciom.ru/index.php?id=1049>, (in Russian).

Report of the Fourth World Conference on Women (Beijing, 4-15 September 1995) 1996, New York, 233 p., viewed 12 March 2018, <http://www.un.org/womenwatch/daw/beijing/pdf/Beijing\%20full\%20report\%20E.pdf>.

The Gender Strategy of the Russian Federation 2002, The Ministry of Labor and Social Development of the Russian Federation, Moscow, viewed 16 January 2018, <http://www.owl.ru/win/docum/rf/strategy/strategy.htm>, (in Russian).

The Gender Strategy of the Russian Federation 2004, The Ministry of Labor and Social Development of the Russian Federation, Moscow, viewed 20 January 2018, <http://womnet.ru/prava/2004/1/4.htm>, (in Russian).

Voronina, OA 2003, Feminism and gender equality, Moscow, 320 p., (in Russian). 